\title{
Polyoxometalate Modified Carbon Supported Pd-Cu Bimetallic Catalyst For Formic Acid Oxidation
}

\author{
Zhiwei Zhu ${ }^{1,2}$, Chenxi $\mathrm{Lu}^{1,2}$, Jianzhi Wang ${ }^{1,2}$, Xiaoxiao Zhang ${ }^{1,2}$, Ning Cai ${ }^{1,2}$, Yanan Xue ${ }^{1,2}$, \\ Weimin Chen ${ }^{1,2}$, Zhiguo Yan ${ }^{1,2}$, Xiaojun Yang ${ }^{1,2}$, Faquan Yu $^{1,2}$, Wei Yang ${ }^{1,3, *}$, Qifeng Tian ${ }^{1,2, *}$ \\ ${ }^{1}$ Key Laboratory of Green Chemical Process of Ministry of Education \& Hubei Key Laboratory of \\ Novel Reactor and Green Chemical Technology (Wuhan Institute of Technology), Wuhan 430205, PR \\ China \\ ${ }^{2}$ School of Chemical Engineering and Pharmacy, Wuhan Institute of Technology, Wuhan 430205, PR \\ China \\ ${ }^{3}$ School of Chemistry and Environmental Engineering, Wuhan Institute of Technology, Wuhan \\ 430205, PR China \\ *E-mail: qftian@ wit.edu.cn (Q. T.), yangweight@126.com (W. Y.)
}

doi: $10.20964 / 2019.12 .81$

Received: 5 August 2019 / Accepted: 5 October 2019 / Published: 29 October 2019

Palladium-copper $(\mathrm{PdCu})$ bimetallic alloy nanoparticles were loaded on the polyoxometalate modified carbon supports (PWA-C) to prepare $\mathrm{Pd}_{\mathrm{x}} \mathrm{Cu}_{\mathrm{y}} / \mathrm{PWA}-\mathrm{C}$ catalyst with different $\mathrm{Pd} / \mathrm{Cu}$ atomic ratios. Highly dispersion catalyst nanoparticles were obtained and its average particle sizes are in the range of 2.75$4.46 \mathrm{~nm}$. Electrochemical measurements indicated that the formic acid electro-oxidation activities of $\mathrm{Pd}_{\mathrm{x}} \mathrm{Cu}_{\mathrm{y}} / \mathrm{PWA}-\mathrm{C}$ catalysts were greatly enhanced than the home made $\mathrm{Pd} / \mathrm{C}$ catalyst. The prepared $\mathrm{Pd}_{\mathrm{x}} \mathrm{Cu}_{\mathrm{y}} / \mathrm{PWA}-\mathrm{C}$ bimetallic catalyst performed superior electrocatalytic activity and stability than $\mathrm{Pd} / \mathrm{C}$ catalyst. Among them, $\mathrm{Pd}_{1} \mathrm{Cu}_{2} / \mathrm{PWA}-\mathrm{C}$ holds the best catalytic performances, whose catalytic activity for formic acid oxidation was improved with a factor of 7.07 as compared to $\mathrm{Pd} / \mathrm{C}$ catalyst. The outstanding electrocatalytic activity and stability of $\mathrm{Pd}_{\mathrm{x}} \mathrm{Cu}_{\mathrm{y}} / \mathrm{PWA}-\mathrm{C}$ catalyst may be attributed to the several effects, which include the smaller catalyst nanoparticle, Pd active sites restoring by PWA modification and $\mathrm{Cu}$ alloying.

Keywords: Formic acid oxidation, $\mathrm{PdCu}$ bimetallic alloy, Electrocatalysis

\section{$\underline{\text { FULL TEXT }}$}

(C) 2019 The Authors. Published by ESG (www.electrochemsci.org). This article is an open access article distributed under the terms and conditions of the Creative Commons Attribution license (http://creativecommons.org/licenses/by/4.0/). 